\title{
Innovation and innovation activities of Bulgarian small and medium-sized enterprises (SMEs)
}

\author{
Sibel Ahmedova ${ }^{1, *}$ \\ ${ }^{1}$ Technical University of Varna, 1, Studentska str., 9000, Varna, Bulgaria
}

\begin{abstract}
Small and medium-sized enterprises are the key driving forces of economic growth and play a decisive role in determining the development of the country's economic structure. They tend to respond swiftly and adapt quickly to the changes that occur in the economic environment by introducing such innovations and innovation activities that address and fulfill their customers' requirements. The primary purpose of the proposed paper, therefore, will be to explore the innovation and innovation activities of SMEs in Bulgaria, and therefrom, to draw the appropriate conclusions and make the relevant scientific generalizations. To that effect, a survey was conducted among 68 SMEs from the food and beverage industry on the territory of Bulgaria, in view of which further guidelines were formulated as to the improved efficiency of their innovation activities.
\end{abstract}

\section{Introduction}

Within the context of dynamic economic changes, innovation and innovation activities are identified as the key driving factors for ensuring sustainable development and attaining the small and medium-sized enterprises' (SMEs) higher competitiveness. This is largely attributable to SMEs' extensive range of advantages that could facilitate the introduction of innovation and make the innovation processes more likely to occur. They have the benefit of creating new jobs; they are more flexible in situations of crisis and are more likely to adapt quickly when the environment changes, internally and externally. They also have opportunities to develop entrepreneurial skills and culture. SMEs practically have the necessary tools to optimize the overall innovation process $[1,5]$.

Capitalising on their ability to generate innovative ideas, SMEs are capable of breaking through the barriers they encounter, unlocking their internal potential for accelerating the process of technology transfer and innovation diffusion, achieving the most consistent economic growth and increasing competitiveness of both individual enterprises and the economy as a whole. It is this particular role of SMEs that comes into focus of the present study and defines its objective, namely: to explore the innovation and innovation activities of Bulgarian SMEs, and therefrom, to draw the appropriate conclusions and make the relevant scientific generalizations $[2,11]$. The object of the study is SMEs from the food and beverage industry, and the subject - their innovation and innovation activities.

\footnotetext{
*Corresponding author: sibel8386@gmail.com
} 


\section{Materials and Methods}

For the purposes of the present paper, a survey was conducted among 68 food and beverage industry SMEs located across the country. In the article are used quantitative and qualitative methods of analysis. The indicators studied are: the types of innovation, the costs of research, training of researchers and cooperation between universities and research organizations.

\section{Innovation and innovation activities of Bulgarian SMEs}

The principal regulatory document encouraging innovation and innovation activities of the Bulgarian enterprises is the "Innovation Strategy for Smart Specialisation of the Republic of Bulgaria" $2014-2020$. The prime target areas of the strategy are research, technology and innovation. Despite the priority objectives expressed therein, Bulgaria remains in the group of modest innovators with its innovation index performance of 49 and indicators that show hardly any positive development when compared to previous years [10,15]. Consideration should, undoubtedly, be given to the effects of the current COVID-19 crisis and its subsequent impact on SMEs innovation development and the economy as a whole. It is very difficult to assess the consequences of the present emergency epidemic situation, as it still persists and it would take time for its repercussions to manifest themselves in full. Nevertheless, over the last year, according to data of the National Statistical Institute (NSI), about $58 \%$ of the SMEs admitted they had implemented innovations, and just over $30 \%$ of them planned to launch innovation activities in the ongoing $2021[12,16]$. The current crisis appears to have a direct effect upon the supply of products, reflected subsequently upon their demand. The demand, however, has not only been reduced, but also structurally changed by the massive introduction and significant growth of online sales, card payments or inclusion in digital sale and supply networks operated by other companies. The NSI data shows that in 2020 the online sales reported by SMEs have increased by 5,6\% as against those of 2019 , and another $4,7 \%$ businesses are planning to launch online products in $2021.5,7 \%$ of the SMEs have introduced other changes in their sales. Such a change, for example, is the introduction of card payments and the provision of sales and supply control to external companies [12].

\section{Innovation and innovation activities of SMEs in the food and beverage industry}

Applying innovations in times of crisis is a complex process that requires significant financial resources. Increasing number of the industry enterprises, however, determined to maintain their market positions, have started investing funds in systems that are more likely to increase their production efficiency and flexibility. Along with the traditional methods of food production and processing, there are some SMEs in the surveyed industry that have also initiated certain innovative solutions associated with the digitalization of the Bulgarian industry. Part of them are closely connected with the application of robotic and automation technologies, Internet of Things, cloud platforms, artificial intelligence and various other innovations, radically transforming the fundamental manufacturing processes and practices in this industry $[3,4]$. The emerging technological development is also affecting the related machinery and equipment, the separate components and auxiliary systems in the food and beverage industry. The results of these changes are attested by the improved labour productivity, enhanced efficiency of management, optimized processes of delivery, reduced cost of production, etc. $[9,13,14]$. There is, accordingly, an upward trend for those food and beverage SMEs that carry out continuous monitoring and control over their technological 
processes in real time, automated management of a large proportion of their operations and regularly performed preventive maintenance $[6,7,9]$.

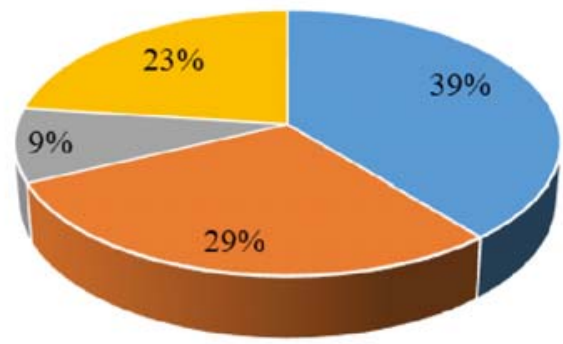

- Product innovation

" Technological innovations

- Organizational and managerial innovations

" Marketing innovation

Fig. 1. Innovations in food and beverage SMEs.

As displayed in Fig. 1, in 2020, 39\% of SMEs in the food and beverage industry had initiated product innovation, and $29 \%$ - technological innovations. The greatest share of the product innovations belongs not only to the newly implemented range of products and services but also to those with significantly upgraded functionality or user characteristics of the already existing products. Of the technological innovations with the largest share are those related to the introduction and deployment of new or improved production technology, modern manufacturing equipment necessary for the production of new or improved products and latest software tools for supply flow optimisation and operating cost reduction (fig.1).

As for the marketing innovations, SMEs have achieved changes in their product design or product packaging, product distribution, product marketing or have adopted new pricing methods. In terms of the organisational and management innovations, effectively performed were those related to: the implementation of an integrated monitoring system to exercise control over the company's activities; the introduction of joint production management systems for managing the relevant manufacturing operations or operations related to the supply.

Observed, in 2020 , is a $3 \%$ increase in the value of the costs incurred for purchasing appropriate machine and equipment when compared to the previous year (fig.2). There is also a discernible growth in the relative share of the improved products and advanced processes accomplished in 2020 in contrast to 2019, when those costs accounted for $15 \%$ of the research and development (R \& D) expenses. In 2019, the share of R \& D expenditures provided for $\mathrm{R} \& \mathrm{D}$ employees was 3 per cent, while in 2020 - as much as 5 per cent. The same trend is also noted with the costs of intellectual property protection. In 2019 they totalled up to $3 \%$ of all expenses and in 2020 - they amounted to 5\%. Such an increase, despite the epidemic situation, is probably due to the fact that the food and beverage industry SMEs have taken prompt actions to respond to the needs of the population forced to spend more time at home during the global lockdown. 


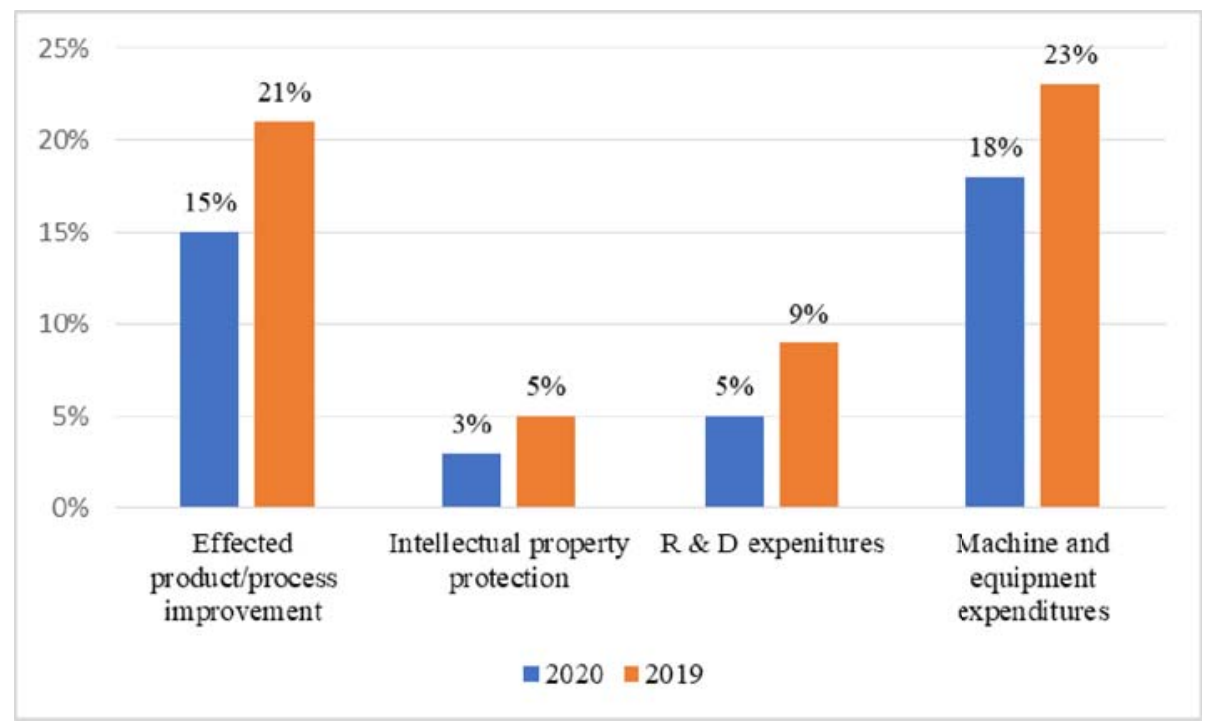

Fig. 2. Research and development expenditures.

Clearly, along with the purchasing of new equipment and machinery and making product and process improvements, the SMEs under study had also provided additional staff training programs to help employees develop their skills and enhance their qualifications. Moreover, further training was yet required in connection with the introduced anti-epidemic measures.

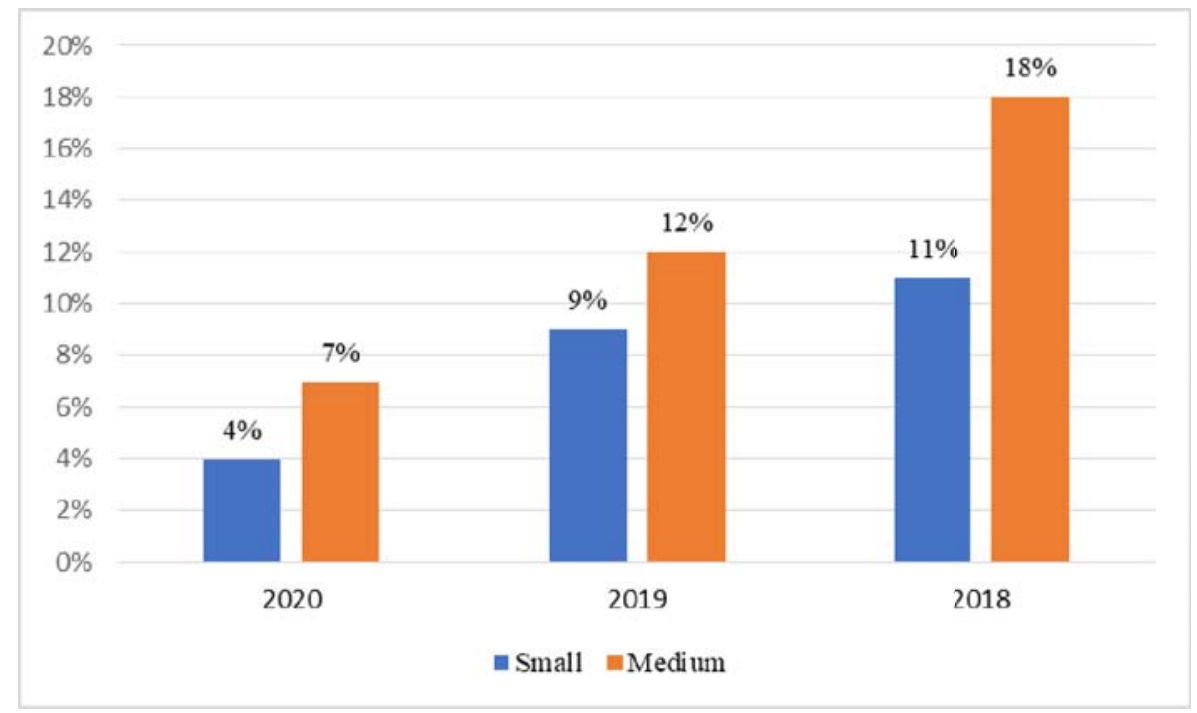

Fig. 3 Provision of further training courses for R \& D employees to upgrade their skills and enhance their qualifications.

The data presented in Fig. 3 reveals that unlike the small-sized enterprises, the medium ones were able to conduct more training to improve their employee R \& D skills and assurance of safe and healthy working conditions. In 2019 , there was a $1 \%$ decline in the relative share of expenses incurred by the medium-sized enterprises for training R \& D employees. In 2020, however, the indicator again returns to its 2018 level - 7\%. A decline in the indicator is also detected in the small-sized enterprises. Its 2018 value of $5 \%$ dropped by $1 \%$ in 2019 to preserve the level of $4 \%$ in the next two years. 
The interaction of food and beverage industry SMEs with higher education institutions and research centres is of utmost importance for the introduction of innovation and innovation activities. For the period of 2018 - 2020, there was a marked tendency to reduce the number of collaborative projects between businesses, research centres and higher education institutions. In the case of the medium-sized enterprises, the cut down amounts to $4 \%$, and for small enterprises $-2 \%$ for the entire period under review (fig. 4 ).

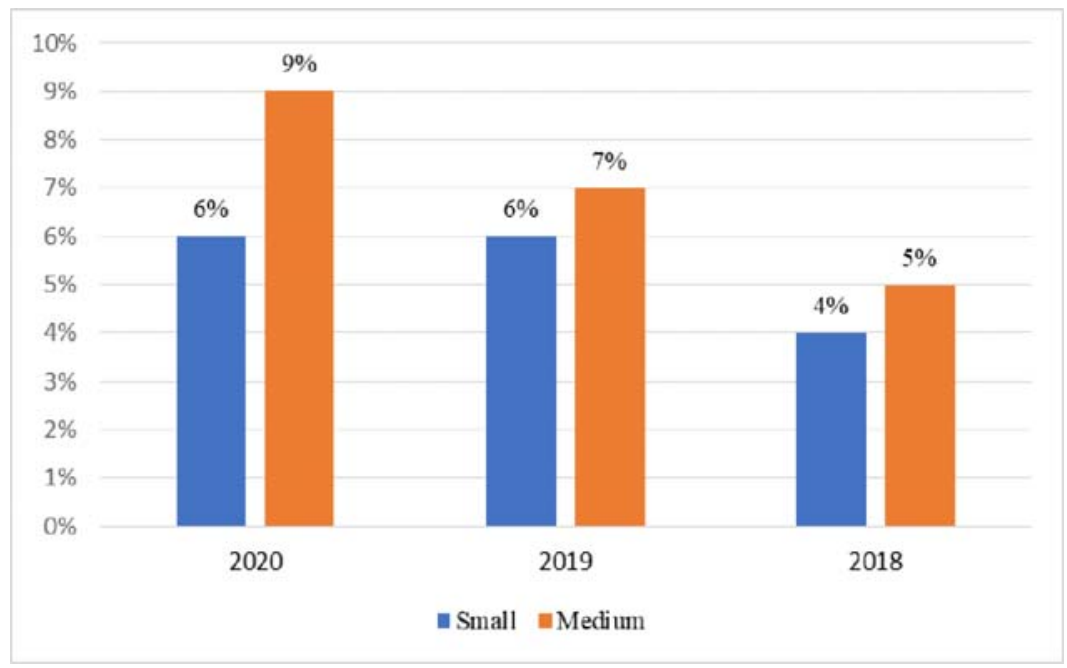

Fig. 4. Collaboration between SMEs with higher education institutions and research centres.

Despite the unpredictability of the current COVID-19 situation, SMEs have a more optimistic outlook for the year to date. $43 \%$ of the medium-sized food and beverage enterprises have planned to innovate and improve their innovation activities in $2021.30 \%$ of the small enterprises have also set up to innovate and improve their innovation performance (fig.5).

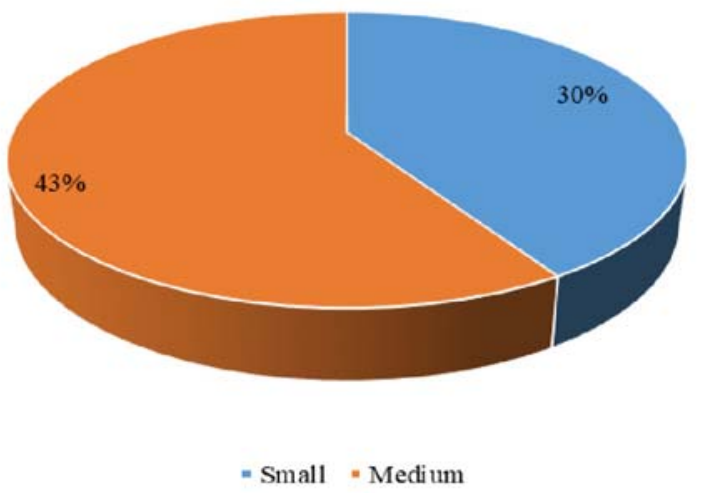

Fig. 5. Planned innovations and innovation activities in 2021.

The main areas of innovation that food and beverage industry SMEs plan to accomplish in 2021 are:

- implementing new product introduction processes and new manufacturing models;

- conducting research and development activities; 
- purchasing machine and equipment;

- acquisition of intangible assets as driving forces of enterprise innovation.

\section{Discussion}

The analysis provides an opportunity to identify the strengths and weaknesses, opportunities and threats to Bulgarian SMEs in the food industry. The analysis of the innovations and the innovation activity of the SMEs from the food industry in Bulgaria shows that:

- the level of organizational and managerial innovation is still relatively low;

- most of the companies invest in machinery and equipment and improvement of business processes;

- investments in intellectual property protection and $R \& D$ expenditures are very low;

- the share of the conducted trainings for raising the qualification of the researchers is low;

- SME cooperation with higher education institutions and research institutes is still not well developed

The identified weaknesses should be a priority of national policy.

\section{Conclusion}

In the light of what has been discussed so far in the present paper, it seems that the main sector capable of increasing its $R \& D$ expenditures, despite the epidemic emergency situation, is the SMEs sector of the food and beverage industry. Although COVID-19 continues to pose a serious threat to both the national and global economy, there are certain business opportunities that can benefit the enterprises in the sector under consideration. Changes are taking place in all areas of the food and beverage industry and it is these particular changes that create the prerequisites for the possible growth of the sector under survey and are likely to facilitate the implementation of innovations and innovation activities. Against such a background, food and beverage SMEs should devote their efforts on:

- developing entrepreneurial and innovative culture within the industry enterprises;

- increasing the proportion of investments in human capital;

- enhancing manufacturing technology and improving their employee experience;

- setting up a system for motivating the employees engaged in research and development;

- raising the levels of technology in the processes of manufacturing by introducing information technology at all levels within the enterprise itself;

- promoting technology transfer;

- encouraging co-operation with other industry enterprises in order to generate and initiate innovations;

- profiting from the opportunities for increased online sales;

- improving and creating their own distribution network;

- obtaining patents and licences for the protection of the enterprises' intellectual property;

- searching for alternative funding sources for innovation and innovation activities;

- increasing the overall expenditure on innovation and innovation activities.

\section{Acknowledgments}

This work was financially supported by grants from the National Program for „Young Scientists and Doctoral Students“, Technical University - Varna, 2021 


\section{Reference}

1. A. Bertello, A. Ferraris, P. De Bernardi, B. Bertoldi, International Entrepreneurship and Management Journal (2021) https://doi.org/10.1007/s11365-020-00727-1

2. V. Belov, Industry 4.0 (2021) DOI: http://dx.doi.org/10.15211/soveurope520164146

3. T. Georgieva, T. Yalamov, Applied Research and Communications Foundation, Economic Sustainability through Innovations (2020)

4. Global Entrepreneurship Monitor (Global Entrepreneurship Research Association (GERA), 2020)

5. Global Innovation Index 2020: Who Will Finance Innovation? https://www.globalinnovationindex.org/

6. J.-L. Hervas-Olivera, F. Sempere-Ripollb, C. Boronat-Mollb, Technological Forecasting \& Social Change 162, 120338 (2021)

7. I. Ivanov, T. Lukyanova, L. Orlova, IOP Conf. Series: Materials Science and Engineering 753, 082023 (2020) doi:10.1088/1757-899X/753/8/082023

8. World Competitiveness Ranking (IMD World Competitiveness Center, 2020)

9. World Talent Ranking (IMD World Competitiveness Center, 2020)

10. INSEAD The Global Talent Competitiveness Index 2019 (Fontainebleau, France, 2019)

11. INSEAD: The Global Talent Competitiveness Index 2020, Global Talent in the Age of Artificial Intelligence (Fontainebleau, France, 2020)

12. Innovation Strategy for Smart Specialisation of the Republic of Bulgaria (2014 - 2020)

13. A.E. Karlik, S.A. Krechko, V.V. Platonov, MIR (Modernization. Innovations. Development) 3(31) (2017) https://cyberleninka.ru/article/n/promyshlennayakooperatsiya-stranchlenoveaes-v-perspektive-tsifrovoy-ekonomik

14. Regional Innovation Scoreboard (National Statistical Institute (NSI), 2019) https://interactivetool.eu/RIS/index.html

15. The IMD World Competitiveness Ranking, IMD World Competitiveness Center, https://www.imd.org/wcc/world-competitiveness-center/

16. The Geography of Europe's Brain Business Jobs: Index, European Centre for Entrepreneurship and Policy Reform, https://www.ecepr.org/wpcontent/uploads/2020/01/Brain-Business-Jobs-2020-Index.pdf

17. The Global Competitiveness Report, World Economic Forum, https://www.weforum.org/reports/the-global-competitveness-report-2018 